\title{
Microstructural approach and transfer water modelling in highly compacted unsaturated swelling clays
}

\author{
N. Saiyouri ${ }^{1}$, P. Y. Hicher ${ }^{1}$ and D. Tessier ${ }^{2}$ \\ ${ }^{1}$ Laboratoire de Génie Civil de Nantes-Saint Nazaire. Ecole Centrale de Nantes et Université de Nantes. B.P. 92101, \\ 44321 Nantes Cedex 3, France \\ ${ }^{2}$ INRA, Station des Sciences du Sol, Route de Saint Cyr, 78026 Versailles Cedex, France
}

\begin{abstract}
A compacted smectite clay was studied in order to understand the swelling phenomenon. The influence of the sample initial state on the swelling mechanisms was demonstrated. A complete physical-chemical and mineralogical characterization of the clay was achieved using X-ray by reflexion and thermal methods. The X-ray diffraction by transmission method allowed to describe the various levels of the hydrated clay organization and the microstructure evolution. The pore distribution and the water partition are shown. Other important parameters: water retention, inter-layer distances, particle size, number of layers per particle were examined. This information gives the ability to follow the swelling which occurred in two steps, and to calculate the swelling potential versus the water content, or the void ratio.

In application to this study, a water transfer in unsaturated clay was studied with the laws of continuous medium mechanics. A finite difference program was used to examine two cases: prevented and free swelling in an oedometer. In order to take into account the material deformation, the swelling potential was introduced in the diffusion coefficients. The simulation results of the water transfer obtained on this basis, were in good agreement with the experiments.
\end{abstract}

KEY WORDS: X-ray; swelling compacted clay; potential; diffusion; microstructure; water transfer

\section{INTRODUCTION}

The aim of this study was to understand and to model the swelling mechanisms in highly compacted clays, and to integrate these mechanisms into a water transfer calculation in a clay matrix. The practical application concerns, in particular, the construction of barriers in deep nuclear waste repositories.

The work focused on the modelling of clay behaviour based on a microstructural approach of the swelling mechanism. The studied clay is a smectite, highly compacted at small water content, in order to develop very high swelling pressure when hydrated at constant volume in a nuclear waste repository site.

The swelling phenomenon was experimentally studied by an important number of authors. ${ }^{1-4}$ Several modelling works exist also on this subject. ${ }^{5-8}$ The conclusion of all these works is that the macroscopic swelling for sodium or calcium smectites occurs in two microscopic steps: ${ }^{9}$ the first one is the water insertion between the elementary clay layers. Afterwards, spaces of larger sizes are 
filled. The relative importance of the two mechanisms is different when the clay is calcium or sodium. However, the studied clays were usually prepared from gels or powders, i.e. at a very high void ratio. It is therefore important to see if the initial state of the clay specimen will affect the swelling mechanisms.

The second aspect of our work is to introduce these mechanisms in a modelling of water transfer in compacted clay specimens.

Generally, the transfer phenomena are described by partial derivative equations (linear or non-linear), with physical parameters in the continuum of the porous medium. The models are established from the associated physical processes which are mass conservation and power balance-sheet, or Darcy's law for water flow and Fick's law for gas flow. They allow the prediction of space and temporal evolution of hydraulic or chemical or also thermal state in a porous medium. To solve them, one needs the knowledge of initial and boundary conditions, or some macroscopic factors like hydraulic or thermal conductivity or finally diffusion or dispersion coefficients.

To model the transfers in rigid or deformable unsaturated soils, numerical methods using finite element or finite difference program are now mainly used. Philip ${ }^{10,11}$ used an iterative method for horizontal and vertical infiltration. He introduced the Boltzmann transformation and then used a finite difference program to solve the resulting equations. Other works on fluid transfers in porous media with hydromechanical coupling are also presented in the literature. ${ }^{12-14}$

In cases of deformable media, the transfer equations have to be coupled with the mechanical model describing the stress-strain relationship for a given medium. Different approaches have been developed to take into account the mechanical behaviour of unsaturated soils. Several authors ${ }^{15,16}$ showed that the effective stress principle (Terzaghi) is not correct for unsaturated soils. Some others, Matyas et al. ${ }^{17}$ and Fredlund et al. ${ }^{18}$, proposed a description of soil behaviour which uses the constitutive surface area or state surface notion. Gens, ${ }^{19}$ proposed an elastoplastic modelling for unsaturated soils based on an approach which considers an independent role of the stress and the negative pore water pressure.

The main aspect of our work was to study the water transfer introducing the swelling influence on the flow. This question dealt with attention to both experiment validation of the clay hydration, and the microscopic study of the clay especially by the X-ray diffraction method. The numerical code used for the flow simulation was deliberately simplified in order to enable the simple introduction of the underlying mechanisms shown by the microstructural observations. A monodirectional flow was assumed which allowed to simulate a test in a one-dimensional condition, and to validate our approach on two typical cases: free and prevented swelling.

\section{MATERIAL AND METHODS}

The studied clay is called FoCa7 (Fourges-Cahaignes clay) from the Paris Basin. A complete physical-chemical characterization of this material was achieved, which is a smectite-kaolinite clay. The specific surface area was measured using the monoethyl ether ethylene glycol method (EGME) which was developed by Heilmen et al. ${ }^{20}$ The value found was $453.66 \mathrm{~m}^{2} / \mathrm{g}$. Usually in the literature, for a very high content of smectite clay (up to $90 \%$ ), the average value of the specific surface area is about $800 \mathrm{~m}^{2} / \mathrm{g}$. This difference is explained by the natural state of the material which was used in our study, while higher values are obtained on purified samples. The different impurities were determined by thermal analysis and X-ray methods as described later. Nevertheless, it is sufficient to remember that the impurities reduce considerably the specific surface area of a clay. 
The analysis of the nature and quantity of the exchangeable cations (counterions) was performed, and the cationic exchange capacity (CEC) was measured in order to characterize the physical properties of the clay. The results obtained by the Soil Analysis Laboratory at Arras-France are shown in Table I.

These values confirm that the FoCa7 clay is mainly a calcium smectite with a CEC average value comparable to those given in the literature.

The total proportion of cations and the number of exchangeable cations in the FoCa7 clay have also been determined. The results showed that the total calcium quantity present in this material is important. This is compatible with the previous analysis on the ratio of exchangeable calcium. The results also showed that FoCa7 contains a substantial fraction of iron $(5.44 \mathrm{~g} / 100 \mathrm{~g}$ of clay). This is an additional factor which decreases the swelling. Another conclusion is that the total potassium presence indicates the existence of illite in the clay.

In order to determine the mineralogical components of this material, we performed a powder analysis by X-ray apparatus in reflexion which indicated that the mineralogical components are essentially kaolinite and smectite. Because of the natural state of the clay, we noted also the presence of several impurities (quartz, gibbsite and goethite). The smectite fraction present in the sample is very important, around $80 \%$, while only traces of the other components, except the kaolinite. A thermal method allowed to quantify the kaolinite present in the sample (about $\sim 7 \%$ ).

Swelling experiments were performed on initially highly compacted clays. These samples were prepared from a powder which was one dimensionally compacted up to $60 \mathrm{MPa}$ in the oedometer cell used for the hydration experiments. Their initial water content was $\sim 10 \%$, which is the value corresponding to equilibrium with the atmospheric relative humidity of the experimental room (60\% of relative humidity). Knowing the water content and the clay mass, the dry density was obtained by prescribing the total volume of the sample.

A set of experiments was carried out on FoCa7 samples in order to understand the swelling phenomena at the microscopic scale by the X-ray diffraction method. Especially, it is important to know and to explain the location of water between the layers and the water filling spaces in larger pores. Thus, the samples were hydrated from the initial state, to high water content values, by decreasing the imposed suction within every sample.

The methods used were the $\mathrm{pF}$ cells, the Richard's cell apparatus $(<1 \mathrm{MPa})$ and the relative humidity in dessicators. These methods are very well described in Reference 9. The principle for each method is briefly described herein. The first and the second methods are based on pneumatic pressure which is fixed in the cell. The samples are in contact across a porous stone to de-ionized water which hydrates them according to the cell pressure value. They remain in the cell until the equilibrium between this pressure value and their suction is reached. On average it was obtained after 4 or 5 days. The $\mathrm{pF}$ tubes correspond to 0.1 at $100 \mathrm{KPa}$, while the Richard's cell goes up to $2 \mathrm{MPa}$.

Table I. Exchangeable cations and cationic exchange capacity for FoCa 7

\begin{tabular}{ccc}
\hline $\begin{array}{c}\mathrm{CEC} \\
\text { (meq/100 g clay) }\end{array}$ & $\begin{array}{c}\mathrm{Na} \\
\text { (meq/100 g } \\
\text { of clay) }\end{array}$ & $\begin{array}{c}\mathrm{Ca} \\
\text { (meq/100 g } \\
\text { of clay) }\end{array}$ \\
\hline $69 \cdot 1$ & 2.64 & 62.90 \\
\hline
\end{tabular}


In the dessicators, the pressure is imposed to the sample by saturated salt solutions. These salt solutions are chosen to impose a particular relative humidity. The suction values reached by this method are very important (about $100 \mathrm{MPa}$ ). The greater imposed pressure value was $107 \mathrm{MPa}$. The equilibrium was obtained in more than 1 month.

\section{Establishment of moisture profiles-water content and apparent volume}

After equilibrium at each suction level by the three methods described previously, the water content and volume were measured. The water content was determined after heating the sample in an oven at $105^{\circ} \mathrm{C}$ for $48 \mathrm{~h}$. For apparent volume measurements, we used a method developed by Tessier and Berrier: ${ }^{3}$ the volume was determined from the Archimed's pressure exerted on the samples submerged in kerosene (AFNOR standard).

\section{Principle of the X-ray method}

The hydrated samples were also analysed by the X-ray diffraction method in order to evaluate the swelling potential. This X-ray diffraction by transmission is performed on hydrated samples which were prepared at different values of suction, and had their water content and void ratio measured.

The diagrams were obtained by transmission according to Pons. ${ }^{21}$ This method allowed information on the distance evolution between the layers $d_{i}$, on the particle size distribution or on the number of layers per particle $M$. It also gives the probabilities $p_{i}$, to have those values of different quoted parameters.

The interpretation of the diagrams is based on the comparison between theoretical and experimental curves. ${ }^{22,23}$ Figure 1 presents an example at the suction value of $1 \mathrm{MPa}$. The parameters are obtained by a fitting of the theoretical curve compared to the experimental one.

The theoretical curve is obtained from the diffused intensity expression by the system which is crossed by the X-ray beam.

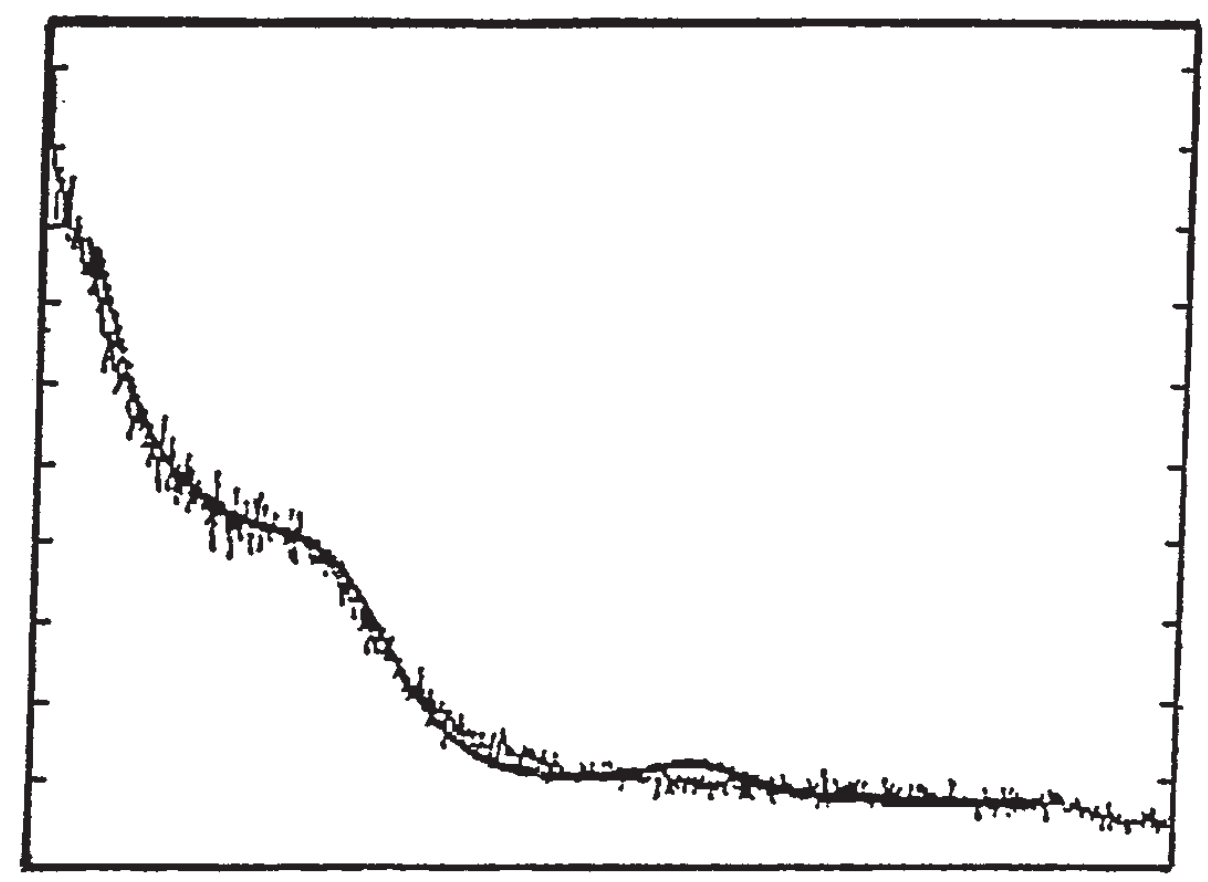

Figure 1. Modelling of the experimental curve obtained by X-ray diffraction on FoCa7 sample at a suction of $1 \mathrm{MPa}$ 
According to Pons et al., ${ }^{22}$ the diffused intensity by a smectite can be written as

$$
I(s)=\frac{1}{2 \pi \Omega} \frac{|F(s)|^{2}}{s^{2}} \sum \alpha(M) G\left(s, M, p_{i}, d_{i}\right)
$$

where $s$ is the diffusion vector, $F(s)$ is the structure factor in the direction perpendicular to the layering, $\alpha(M)$ is the weight distribution in particle thickness, $G(M)$ is the modulation function determined by Mering, ${ }^{1}$ and $G(M)$ can be written as

$$
G\left(s, M, p_{i}, d_{i}\right)=1+2 \operatorname{Re}\left[\sum_{n=1}^{M-1} \frac{M-n}{M} Q^{M}\left(s, p_{i}, d_{i}\right)\right]
$$

where $Q\left(s, p_{i}, d_{i}\right)$ is a function which takes into account the interference between two adjacent layers. ${ }^{24}$

In our case, i.e. where the transition between two layers is done by $r$ translations $d_{1}, d_{2}, \ldots, d_{r}$ with respective probabilities $p_{1}, p_{2}, \ldots, p_{r}$, the $Q\left(s, p_{i}, d_{i}\right)$ function takes the following form: ${ }^{24}$

with

$$
Q(s)=\sum_{i=1}^{r} p_{i} \exp \left(2 \pi i s d_{i}\right)
$$

$$
\sum_{i=1}^{r} p_{i}=1
$$

In the particular case of montmorillonite, the structure factor is known. ${ }^{21}$ Thus, the layer number per particle $M$, and the interlayer distances $d_{i}$ with corresponding probabilities $p_{i}$ can be simultaneously found.

\section{RESULTS AND DISCUSSION}

\section{Water retention measurement. Water content and volume change curves}

The void ratio and the volumetric and mass water content values become very large when the imposed suction values decrease. The water content and the void ratio versus the suction values are first presented in Figures 2 and 3, respectively. The water content value reached at the lower imposed suction value $(1 \mathrm{kPa})$ in the FoCa7 clay is about $68 \%$. This is interpreted as due to the nature of smectite sheets present in the samples which can absorb large quantities of water and promote similar hydration and swelling. However, due to the presence of a more important number of divalent cations $(\mathrm{Ca})$ in $\mathrm{FoCa} 7$ than of monovalent ones $(\mathrm{Na})$, this amount of water content is small if compared to the water content reached for sodium montmorillonite, for example, which can be about $200 \%$ for low suction values.

In order to more clearly present the results concerning the water retention by the clay, the relation between the degree of saturation and the suction pressure can be used. The grain dry weight used is $2.67 \mathrm{~g} / \mathrm{cm}^{3}$ for FoCa7. Figure 4 indicates that the clay is not saturated at the beginning of the cycle, but it becomes saturated at the end.

\section{$X$-ray results and microstructures}

The X-ray analysis gives the distances between the clay layers. These distances correspond to the number of water layers adsorbed between the clay layers. They can be equal to $10,12 \cdot 6,15 \cdot 6$, 


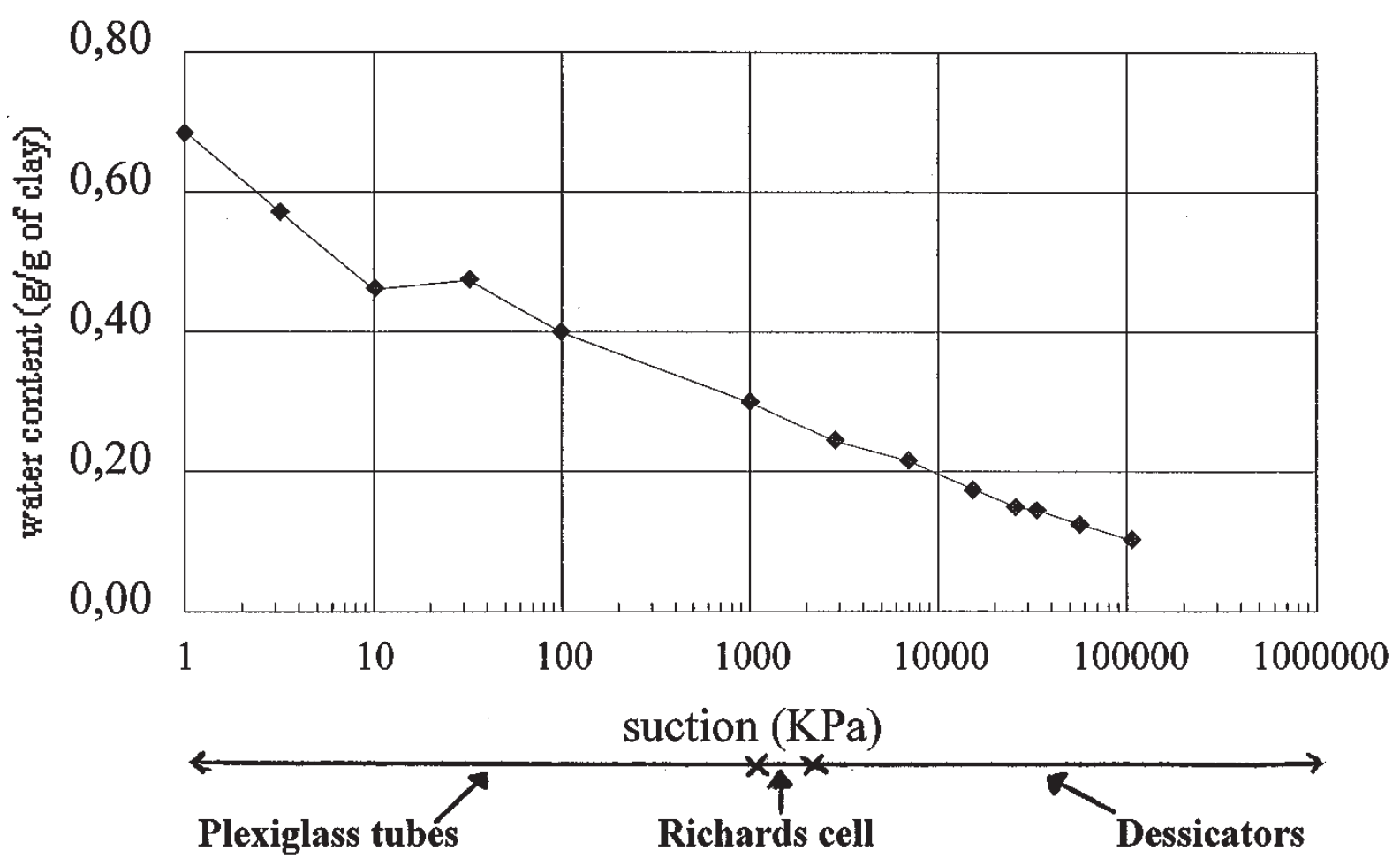

Figure 2. Water content at equilibrium

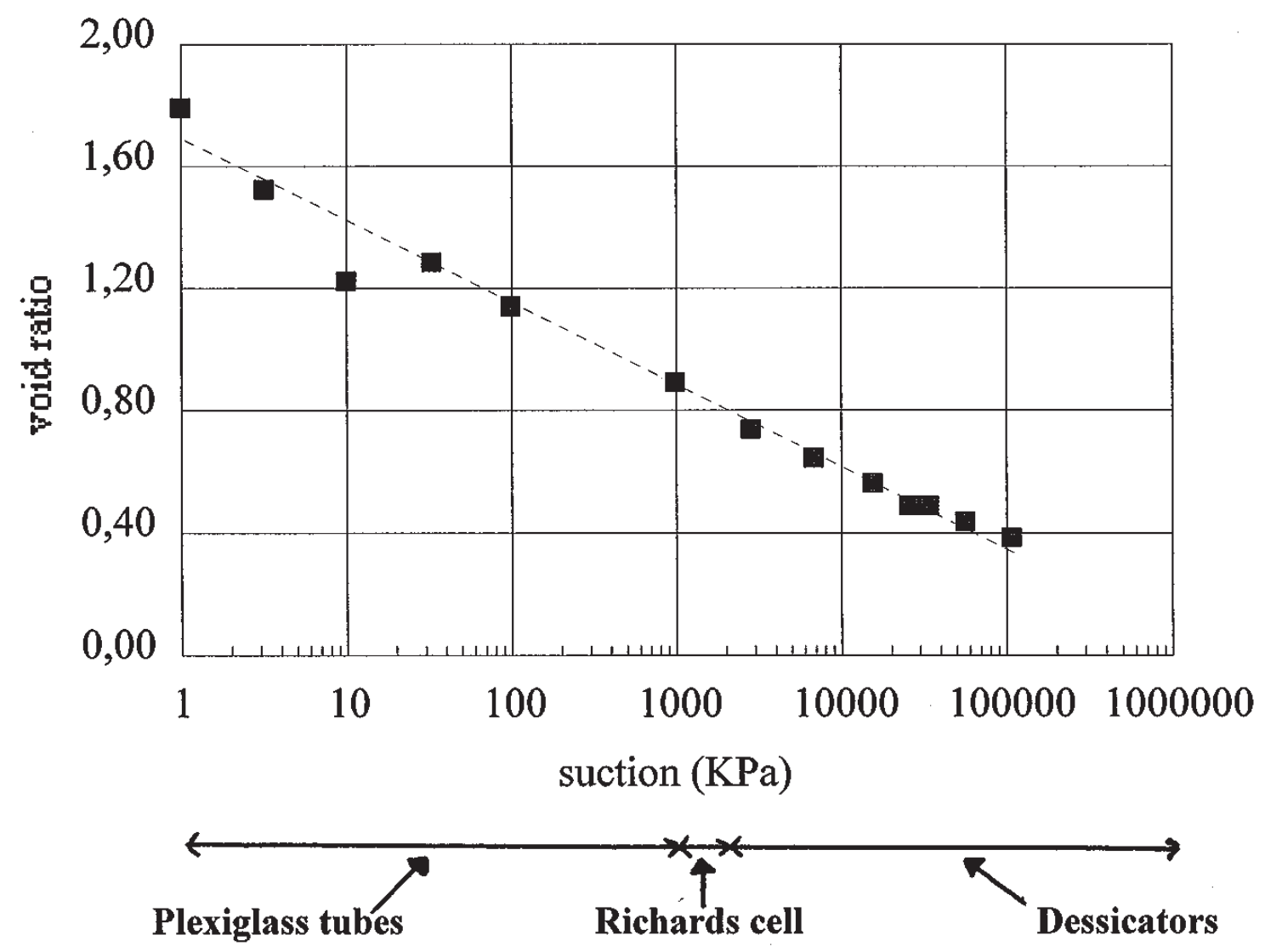

Figure 3. Void ratio versus suction 
18.6 or $21.6 \AA$ which corresponds to $0,1,2,3$, or 4 water layers. Figure 5 gives an example of adsorption of water between the clay layers.

In the following, we present the average layer distances and the clay particle sizes. The number of layers per clay particle decreases as the water content increases in the clay. For the lower value of the water content, a particle is composed of 100 layers (Figure 6). But when the water content increases, the number of layers per particle decreases until reaching only 10 layers

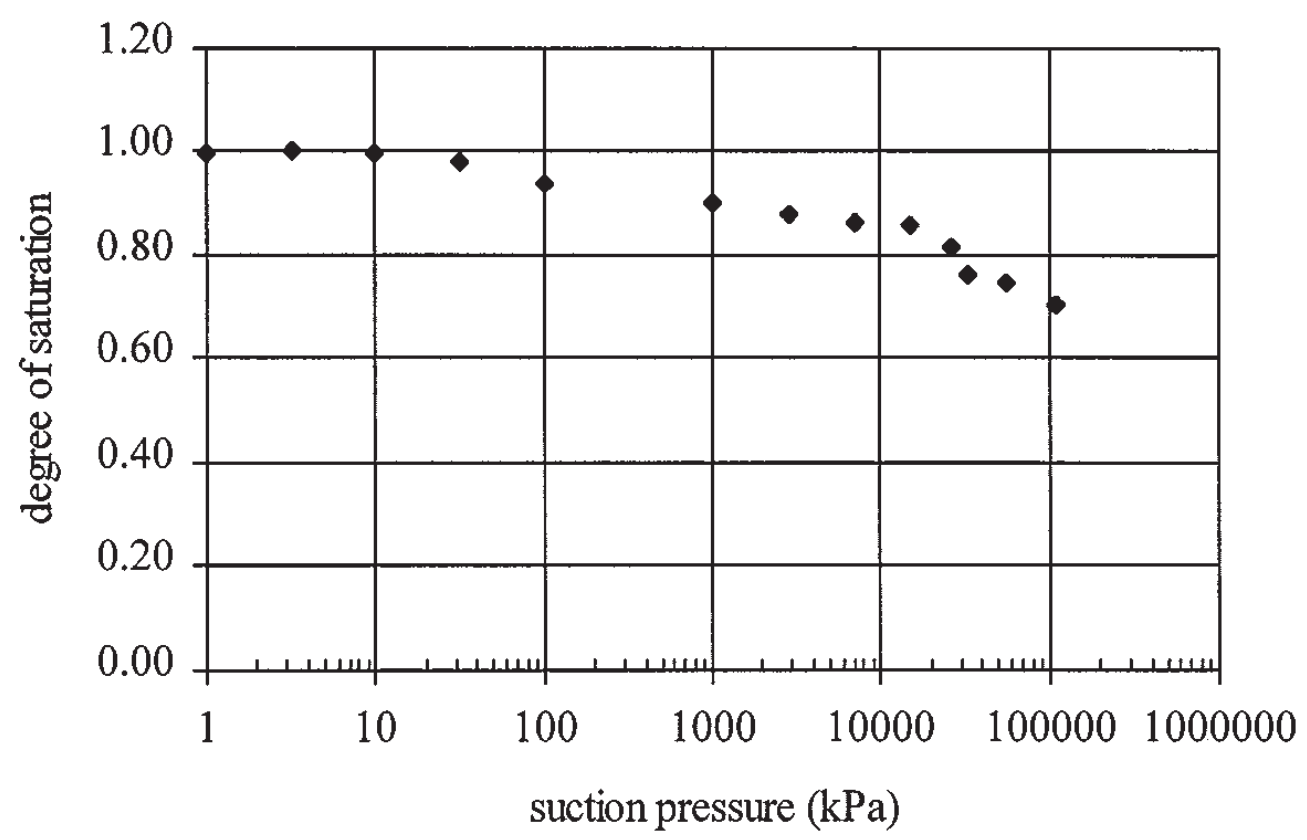

Figure 4. Degree of saturation versus suction pressure

adsorbed water

elementary sheet of montmorillonite

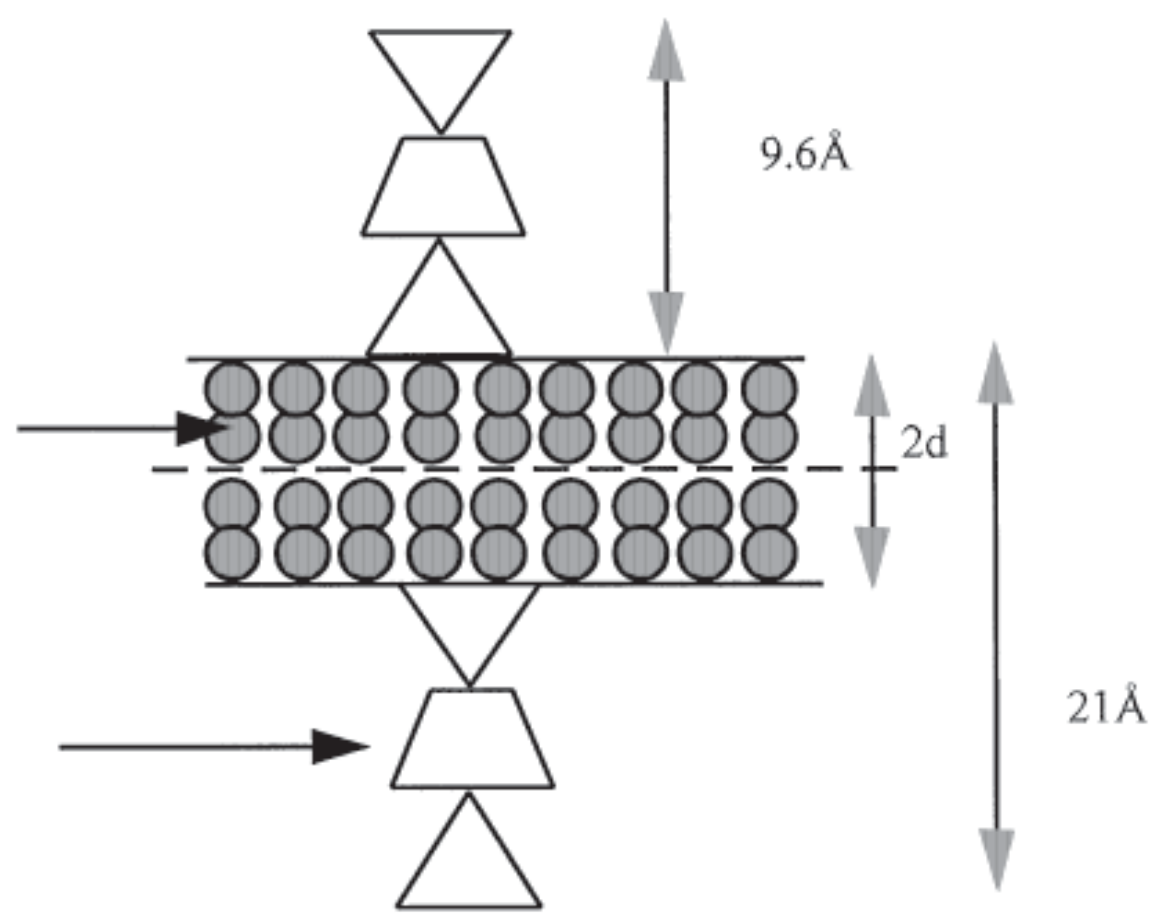

Figure 5. Schematic distance between two layers of montmorillonite 
by particle. The particle size decreases in a ratio of 10 between the initial state and the very hydrated one.

Figure 7 presents the inter-layer distances for $\mathrm{FoCa} 7$, calculated using the Pons model. From the 'dry' state (10\% water content), we can see that a displacement from 15.6 to $18.6 \AA$, was observed from high-to-low values of suction.

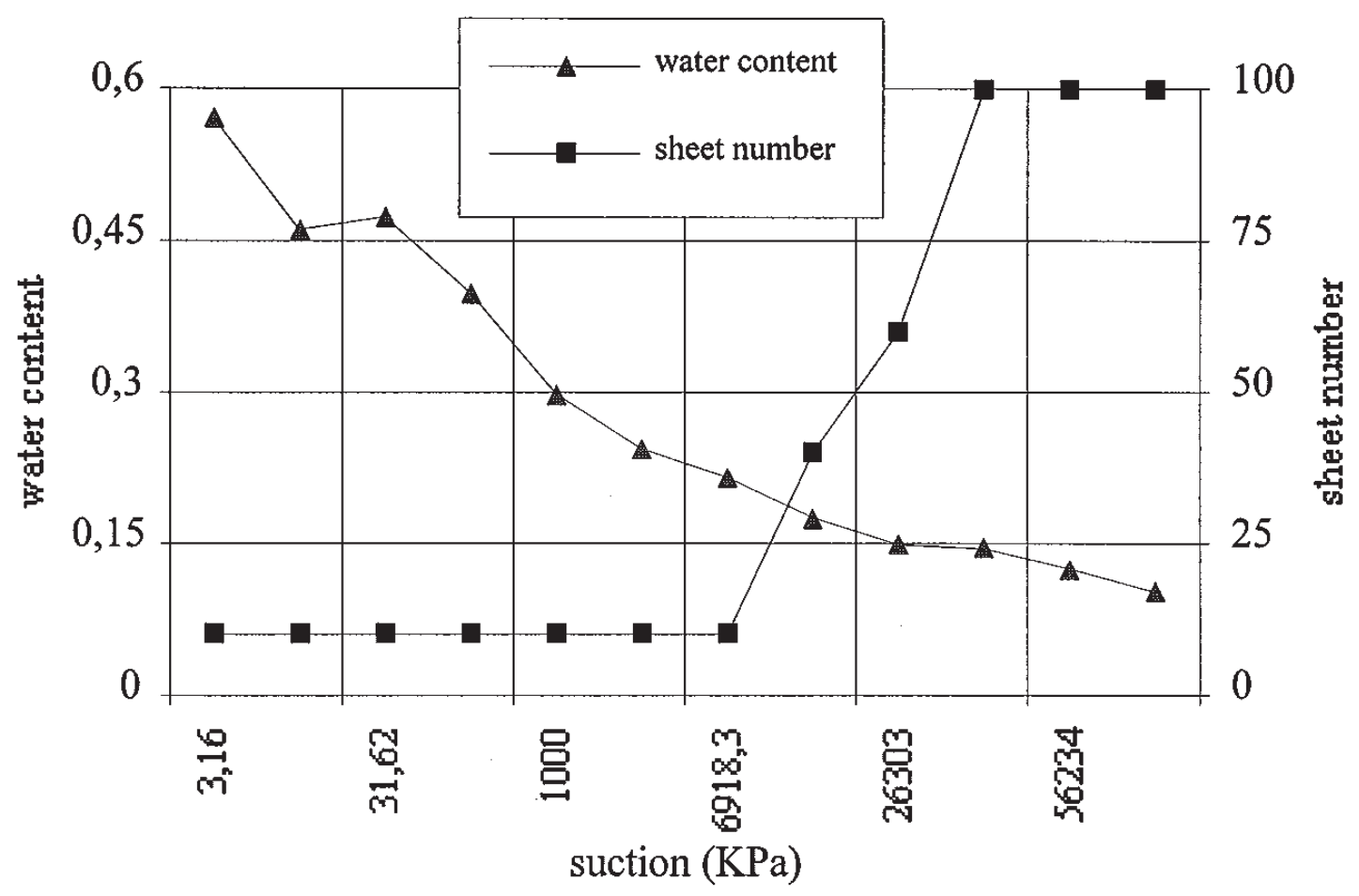

Figure 6. Number of layers per particle and water content of the clay versus suction

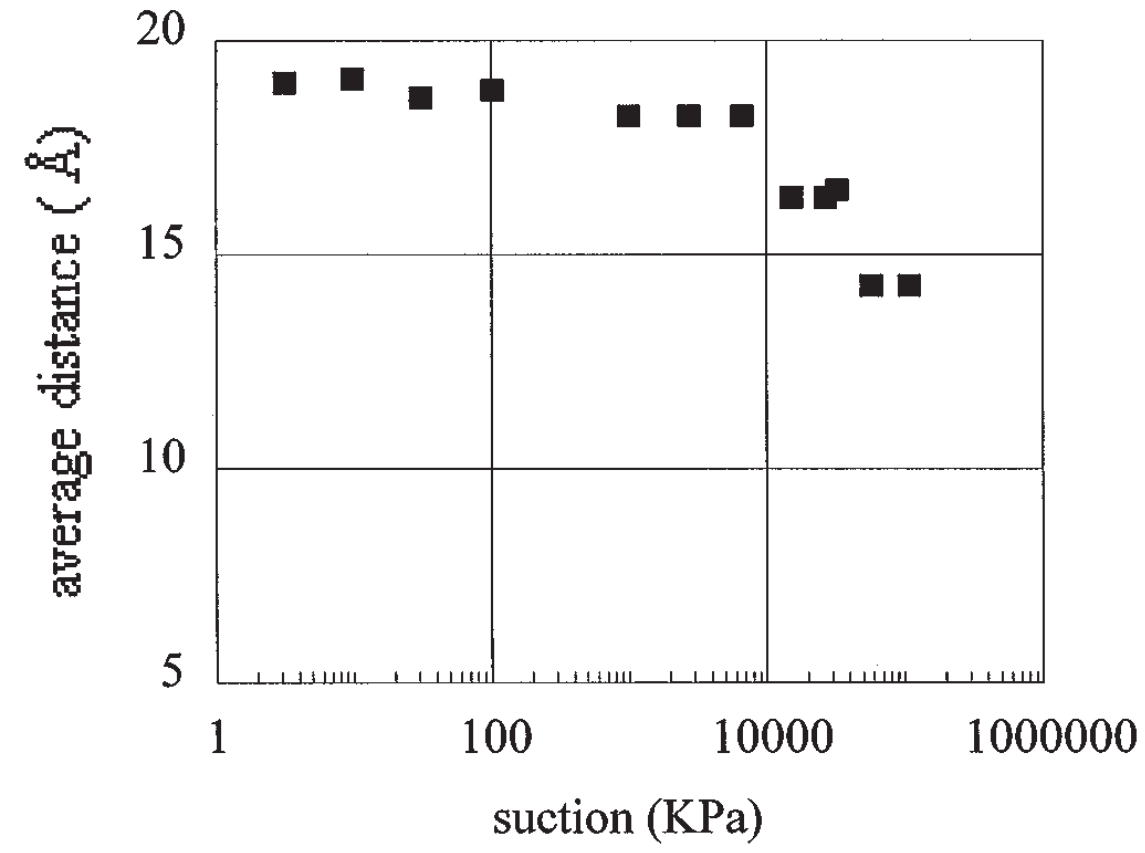

Figure 7. Average distance between layers of clay versus suction 


\section{Swelling mechanism}

Clay particle size change. It is usually reported in the literature that the clay swelling mechanism is mainly due to a change in layer distances. Our work shows that the size of particles is also a very important parameter to understand the clay behaviour, and especially the swelling. As shown in Figure 8, the convention we have chosen is that an aggregate is a set of particles or crystals, with the particles themselves composed of layers.

It appears from our experiments that the swelling mechanism of the clay begins by an adsorption of water between individual clay layers which is accompanied by a decrease of the particle size, or in other words by a subdivision of the clay particles.

Layer distance evolution. In Figure 7, FoCa7 clay presents only one water layer at about $50 \mathrm{MPa}$. We observe that the clay layer distance increases with the water content from 1 to 3 water layers from low to higher water content. When another water layer is adsorbed, the layer distance goes from 12.6 to $15.6 \AA$. This transition arises at a suction of about $7 \mathrm{MPa}$. The same behaviour had been observed by Delvaux ${ }^{23}$ for another smectitic clay: a sodium montmorillonite. We know, however, after Delvaux et al., and also after experiments performed ${ }^{25}$ and not shown in this paper, that another transition appears at about $60 \mathrm{kPa}$ for a sodium clay and leads to a layer spacing of $21.6 \AA$ (four water layers) and never more. We then conclude that the crystal swelling is limited to four water layers, while according to the study ${ }^{23}$ at low suctions the layer distance can reach $100 \AA$. Our interpretation is that the initial strongly compacted state of the clay limited the crystal swelling to four water layers.

Limited crystal swelling. The hydration is accompanied by the insertion of water layers between the clay layers, which causes a division of the initial particles (see Figure 9). The resulting smaller particles are separated by distances which increase considerably up to some water layers. The

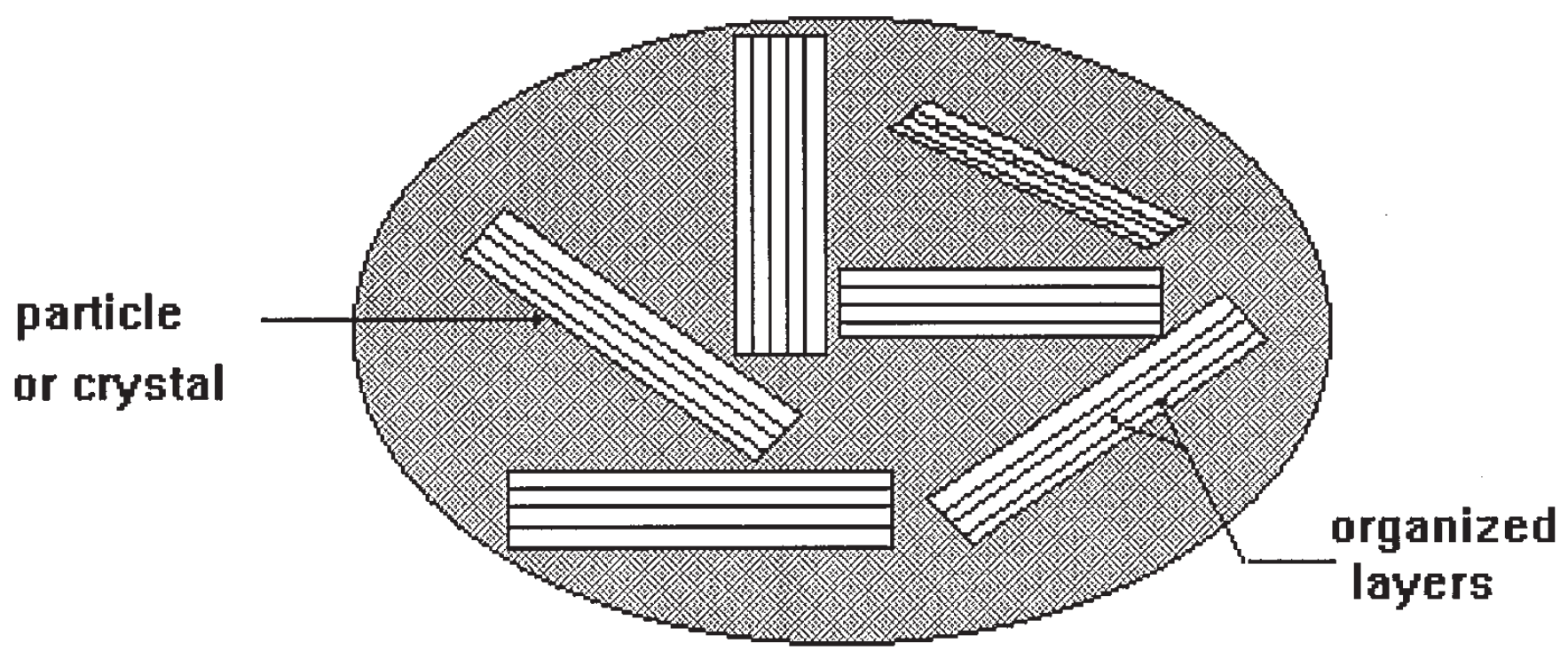

particle aggregate

Figure 8. Notion of clay particle, cristal and aggregate structure 


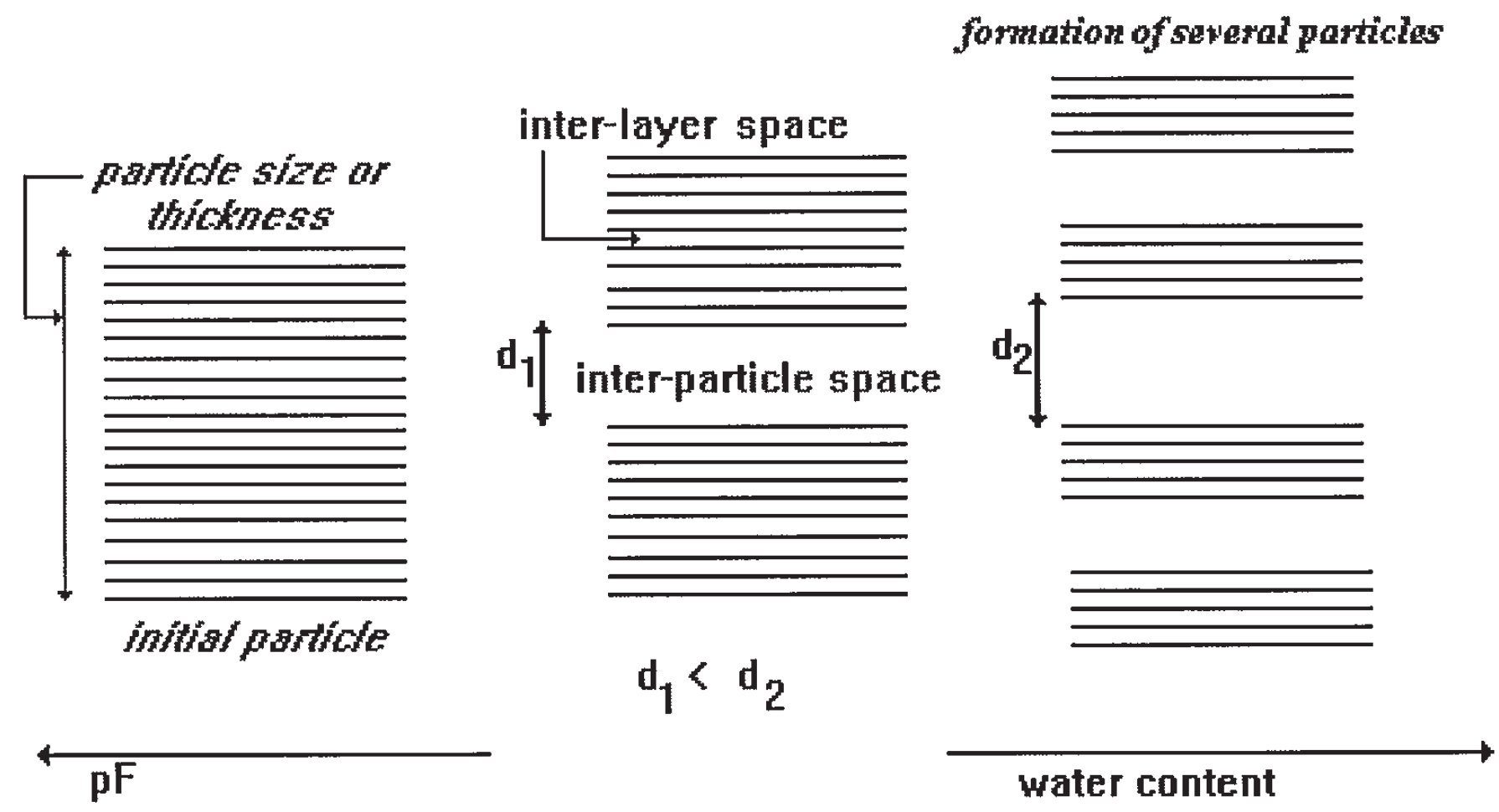

Figure 9. Swelling mechanism interpretation

conclusion that it exists in spaces other than interlayer ones, comes from the calculation of water ratio in the interlayers compared to the total water in the clay. This question will be discussed in the following paragraph.

External water. The Pons model allows us to estimate the interlayer sizes in the hydrated clay by the probabilities $p_{i}$ to have one to four water layers in the interlayer spaces. The product of the specific surface area which is the surface that water can reach, by the size of water molecule gives the elementary volume of water. This later can be multiplied by the water layer number and the probability to have it in order to obtain the total water in each porosity scale. The results are the water volumes $V 1, V 2, V 3$ and $V 4$ which correspond to the water quantity in the spaces containing, respectively, one, two, three or four water layers. The difference between the measured total water content and the water in inter-layer spaces, i.e. the $V 1, V 2, V 3$, and $V 4$, constitutes the external water filling interparticles pores. These water volumes are presented in Figure 10. The external water is also present in the same graph which shows that the external water appears very important compared to the different $V 1, \ldots, V 4$ when the suction values are small (several $\mathrm{KPa}$ ). However, when the water content decreases, the external water decreases too, and the proportion of water in the volumes $V 1, \ldots, V 4$ increases. It means that when the clay approaches a dry state, water is only present between the clay layers and there is nearly no external water. But when wet states are reached, the external water becomes important and its proportion compared to the interlayer water is higher.

It can be also deduced that when the suction is important, the volumes $V 1$ and $V 2$ are prevailing and when the suction decreases, the proportion of the volumes $V 3$ and $V 4$ increases. This means that in a very hydrated clay the probability to have clay layers separated by one or two water layers is very weak compared to the one to have three or four water layer. Moreover, the external water is simultaneously more important than the interlayer water. 

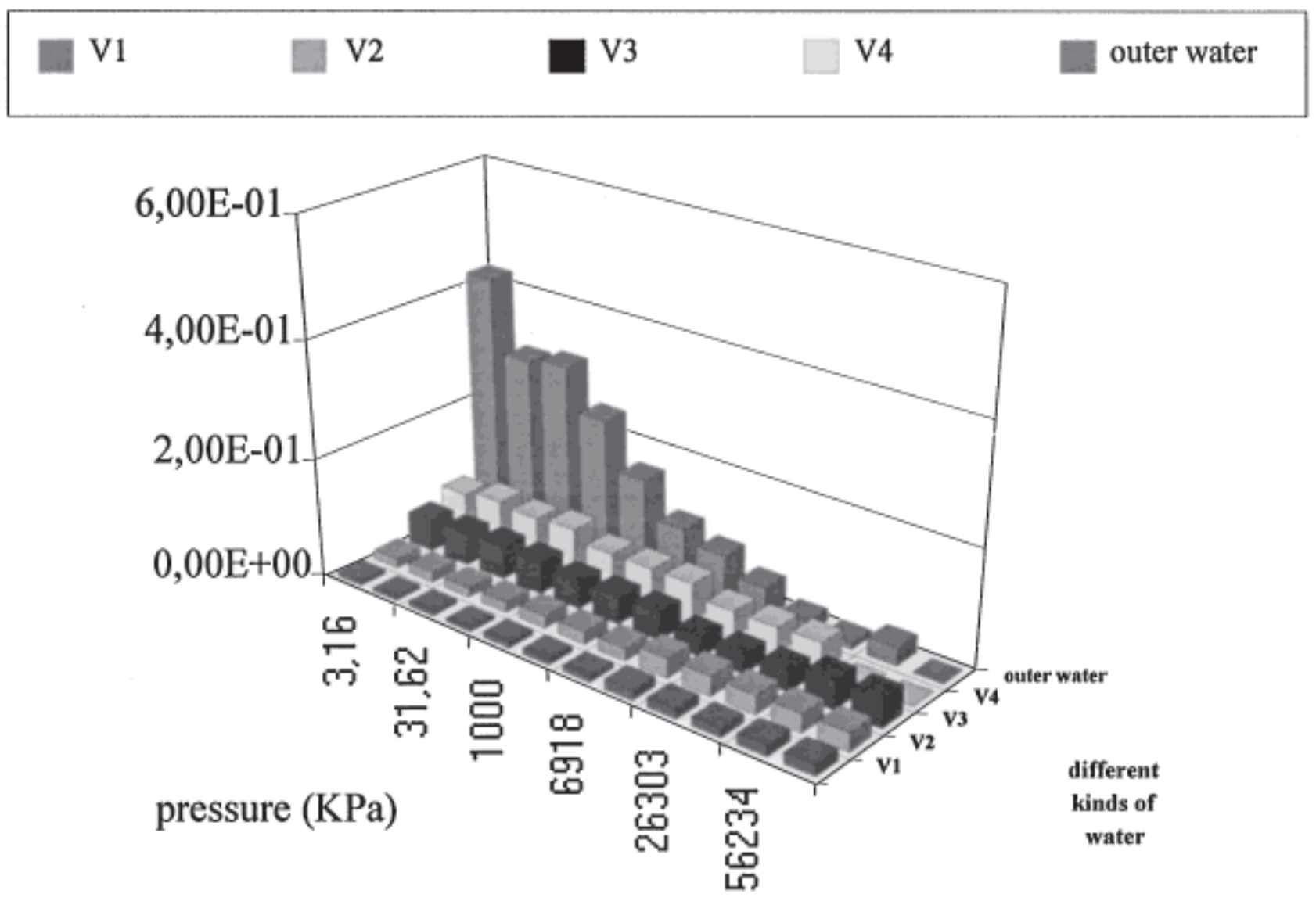

Figure 10. Water between layers and external water

Swelling Modelling. After having established the existence of different kinds of water corresponding to different pore sizes, we can say that the swelling phenomenon in our clay occurs in two steps: first the insertion of adsorbed water between the clay layers, which is accompanied by the division of initial particles (in other words, the surface area is changing). Afterwards the particles are separated by distances which are greater than $21.6 \AA$. We can try to calculate those distances. This can be based on the water quantities already assessed in the previous paragraph (i.e. the external water), the number of layers and the specific surface area. The curve in Figure 11 presents the calculated distances versus the swelling pressure which represents the imposed pressure. We can therefore deduce the relationship between the external water (or interparticle distance) and the corresponding swelling pressure.

It can be noticed that a linear relationship between the distances and the log of the swelling pressure is obtained. We can therefore propose a model taking into account the overall amount of water as a function of the swelling pressure. In this model the interlayer distances can be plotted horizontally (Figure 12). If we try to achieve the same representation for FoCa7 clay, we take the results of Figure 11, and we add the values of interlayer distances versus the swelling pressure. This leads to Figure 13. We can say that the water between the clay layers gives a swelling less important than the interparticle water because of the repulsion with high distances between particles. Those distances are compatible with the existence of a diffuse double layer around the particle surface. 


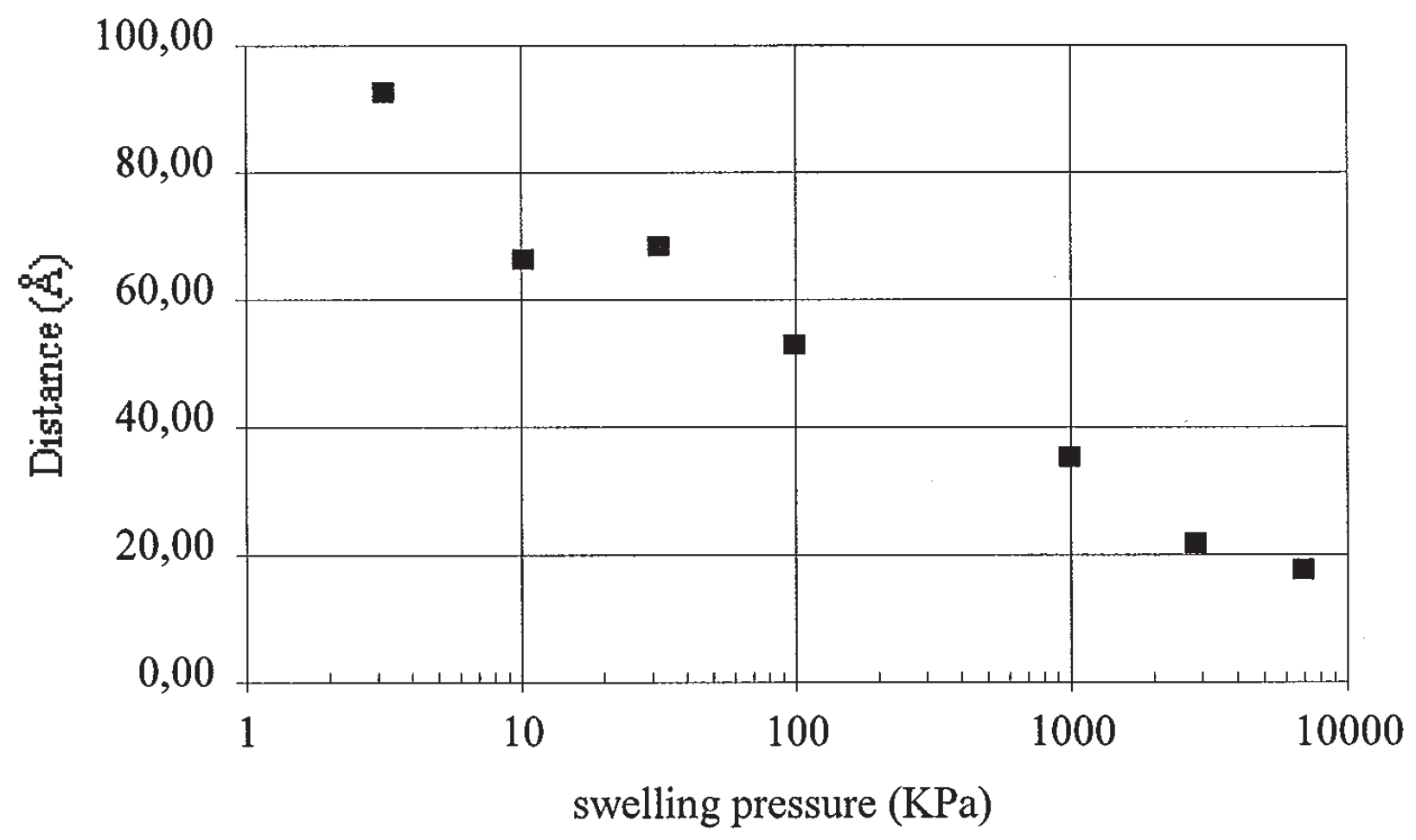

Figure 11. No inter-layer distances versus swelling pressure

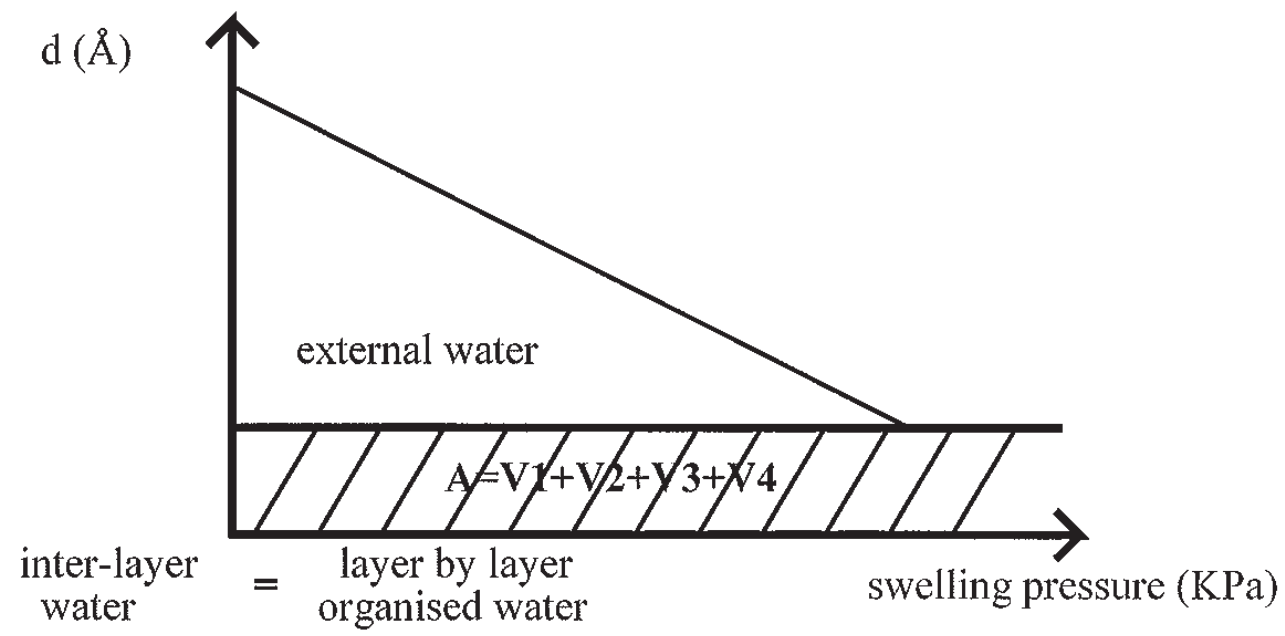

Figure 12. Representation of inter-particular and inter-layer distance versus the swelling pressure (Model)

\section{APPLICATION TO THE MODELLING OF WATER TRANSFER}

Having proposed a model of swelling at a microscale, we will try now to introduce it at a macroscale. A part of the difficulty to understand the unsaturated soils behaviour arises because of the phenomenon associated with volume change. Some specific assumptions concerning the description of the soil potential must be considered first.

$\psi_{\mathrm{w}}(\mathrm{w}=$ water $)$ is the total potential in the system and it can be composed of the sum of several terms: ${ }^{26,27}$

$$
\mathrm{d} \psi_{\mathrm{w}}=-\left(S_{\mathrm{ws}} / g\right) \mathrm{d} T+\mathrm{d} \psi_{\mathrm{p}}+\mathrm{d} \psi_{\mathrm{m}}+\mathrm{d} \psi_{\mathrm{n}}+\mathrm{d} \psi_{\mathrm{z}}
$$




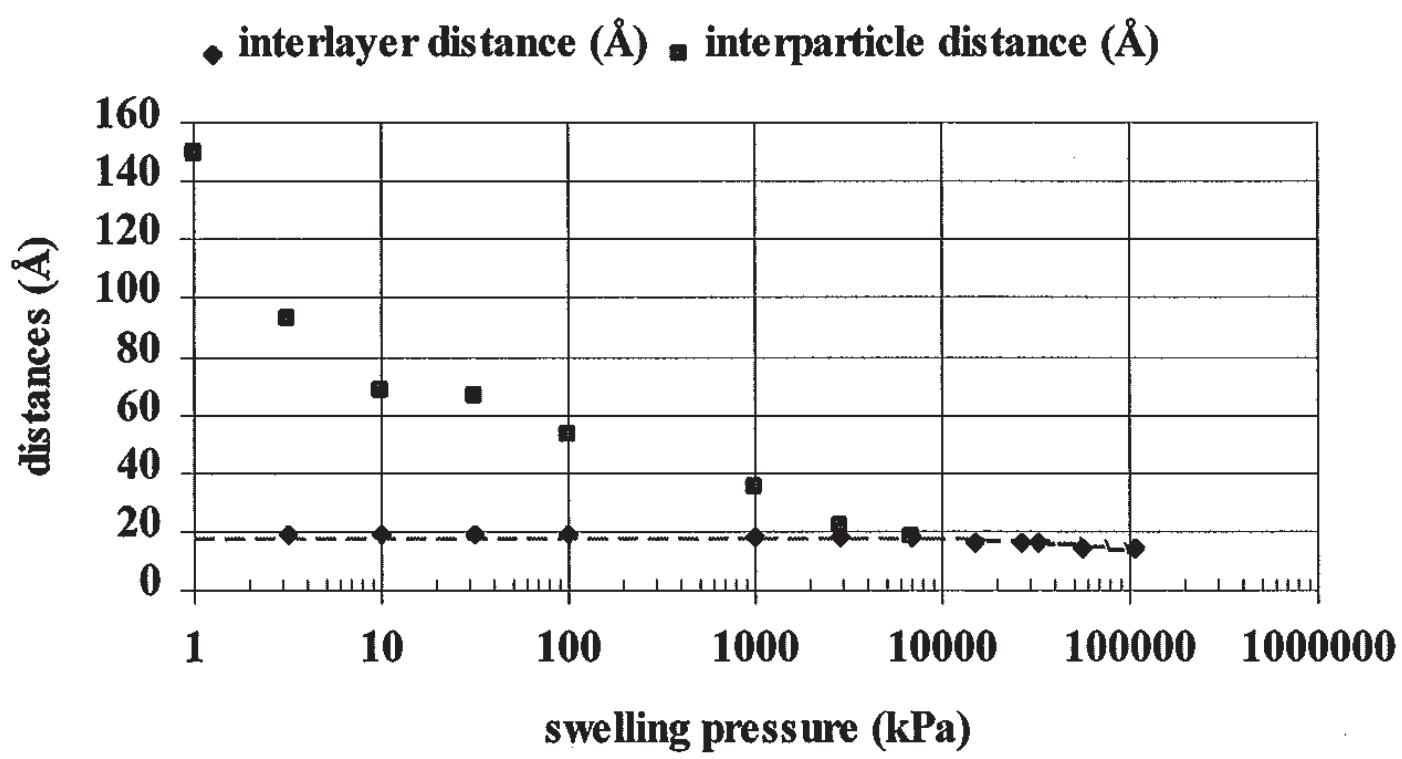

Figure 13. Inter-particular and inter-layer separation versus the swelling pressure for FoCa7

$S_{\mathrm{ws}}$ is the specific entropy, $\psi_{\mathrm{p}}$ is the applied pressure potential, corresponding to the external applied pressure, $\psi_{\mathrm{m}}$ is the matricial potential, corresponding to the suction pressure in the soil, $\psi_{\mathrm{n}}$ is the pneumatic potential, corresponding to the air pressure and $\psi_{\mathrm{z}}$ is the gravitational potential corresponding to the gravitation effect.

In condition of isothermy $(\mathrm{d} t=0)$ and air at atmospheric pressure, we can write

$$
\psi_{\mathrm{w}}=\psi_{\mathrm{p}}+\psi_{\mathrm{m}}+\psi_{\mathrm{z}}
$$

In the case of swelling, the applied potential is the swelling potential, i.e. we can write

$$
\psi_{\mathrm{w}}=\psi_{\mathrm{m}}+\psi_{\mathrm{s}}+\psi_{\mathrm{z}}
$$

$\psi_{\mathrm{s}}$ is the swelling potential.

Swelling clays develop high suction and swelling potential values, the gravitational potential can, thus, be neglected compared to the two other terms.

Two cases are presented: prevented and free swelling.

In the prevented swelling case (no deformed matrix), no volume change occurs. The single contribution is that of the suction potential, i.e.

$$
\psi_{\mathrm{w}}=\psi_{\mathrm{m}}
$$

When the swelling is free and in order to take into account the swelling deformation, we introduced the potential of swelling in the total water potential of the sample, instead of the suction potential alone in the case of no deformed matrix. The swelling potential was the one measured experimentally, more precisely, deduced from the swelling pressure presented in the previous paragraphs. So, the swelling potential was added to the suction potential to take into account the total potential in the sample. This represents the originality of our approach concerning the water transfer study in swelling soils.

$$
\psi_{\mathrm{w}}=\psi_{\mathrm{m}}+\psi_{\mathrm{s}}
$$




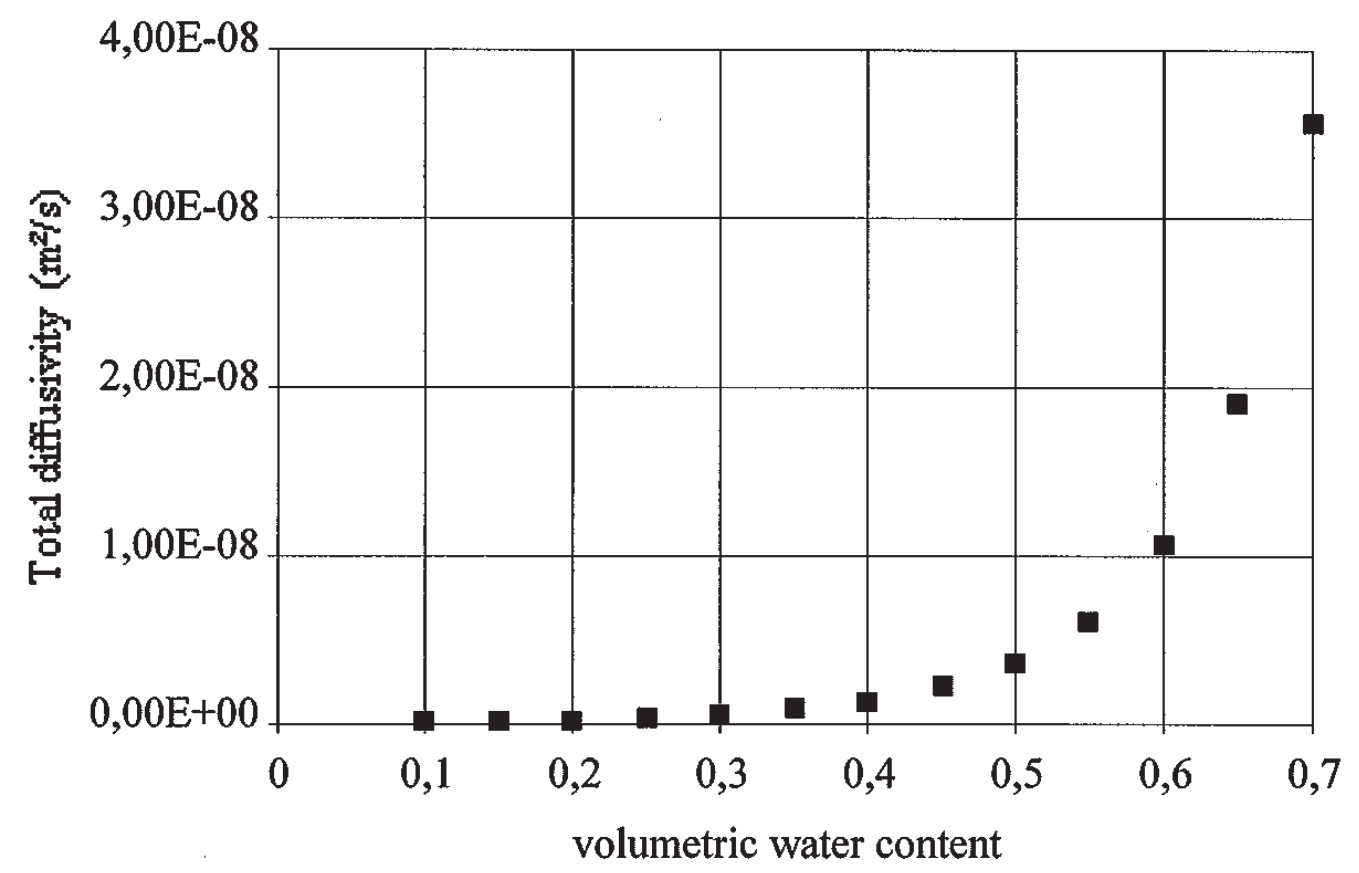

Figure 14. Diffusivity function due to the total potential

If $D_{\mathrm{w}}\left(\theta_{\mathrm{w}}\right)$ is the Darcy's diffusivity (or diffusion) coefficient, it can be related to the potential derivative as follows (Figure 14):

$$
D_{\mathrm{w}}\left(\theta_{\mathrm{w}}\right)=k_{\mathrm{w}} \frac{\partial \psi_{\mathrm{w}}}{\partial \theta_{\mathrm{w}}}
$$

where $K_{\mathrm{w}}$ is the permeability to water coefficient (called $K$ in the following). $\theta_{\mathrm{w}}$ is the concentration or water content.

In the non-deformed matrix case, the diffusion term can be written as

$$
\begin{aligned}
& D_{\mathrm{w}}=D_{\mathrm{m}} \\
& D_{\mathrm{m}}=-K \frac{\partial \psi_{\mathrm{m}}}{\partial \theta}
\end{aligned}
$$

$D_{\mathrm{m}}$ is the matricial diffusion (obtained from the suction).

In the free swelling case the diffusion coefficient can be written as

$$
D_{\mathrm{w}}=D_{\mathrm{m}}+D_{\mathrm{s}}
$$

where $D_{\mathrm{s}}=-K \partial \psi_{\mathrm{s}} / \partial \theta$

$D_{\mathrm{s}}$ is the swelling diffusion (obtained from swelling potential).

In order to test the validity of our approach, we considered a simple case of one-dimensional swelling that we had experimental results at our disposal, on the same clay FoCa7. In the tests performed by $\operatorname{Imbert}^{28}$ the clay sample was $51 \mathrm{~mm}$ high, its initial water content was $10 \%$ and the water content at saturation was $52 \%$. The test consisted to humidify the sample from the bottom and to follow the saturation front evolution in an oedometric cell, by the gamma spectroscopy method. The profiles of water content and dry density of the clay were obtained every $3 \mathrm{~mm}$ from the bottom of the sample, during all the tests (Figure 15). Two cases were studied: free and prevented volume change. 


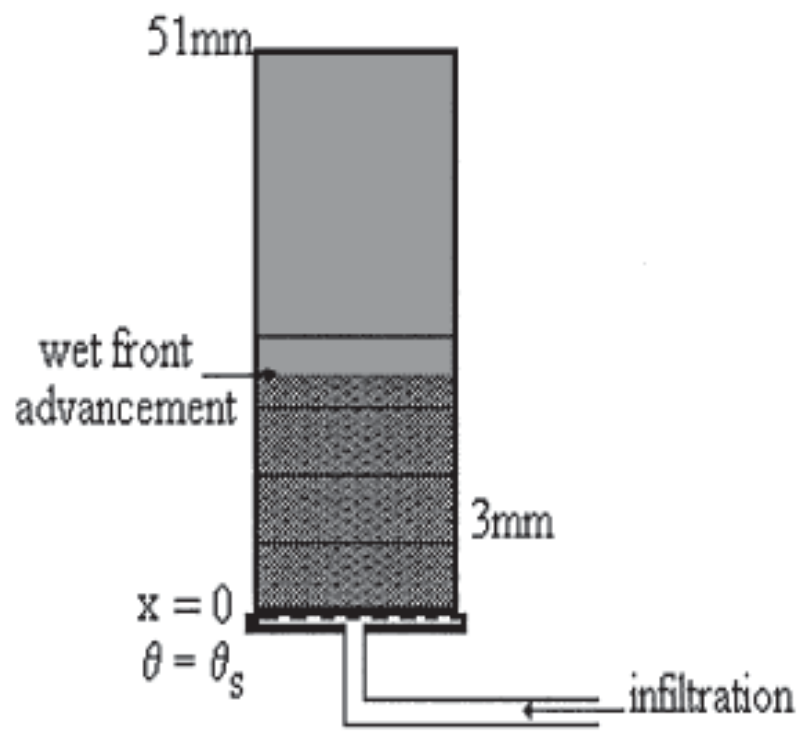

Figure 15. Experimental principle of oedometric hydration of the clay samples

The equations controlling the water flow have been studied by several authors. ${ }^{29-31}$ A finite difference method was used in order to solve these equations in a one-dimensional case. The aim of this section is to demonstrate that using the equations discussed before, we are able to model the water flow with some specific boundary conditions according to each case. The results of calculation will be presented and compared to experimental results in the cases of no-volume change and free swelling for a highly compacted specimen of FoCa7 clay.

The hypotheses are the following:

(a) flows are one-dimensional and deformations are small.

(b) Effect of gravity is neglected.

(c) Darcy's law can be applied.

The flow in porous media is governed by two equations: mass conservation for all phases (i), with concentration $\theta_{i}$ and Darcy's law for fluid flow behaviour. The combination of these two equations gives the transfer equation. ${ }^{32,33}$ In the one-dimensional case, for the aqueous phase only, the obtained standard diffusion equation with non-linear coefficients which is called Richard's equation can be written:

$$
\frac{\partial \theta_{\mathrm{w}}}{\partial t}=\frac{\partial}{\partial x}\left(D\left(\theta_{\mathrm{w}}\right) \frac{\partial \theta_{\mathrm{w}}}{\partial x}\right)
$$

where $\Psi_{\mathrm{w}}$ is the total potential in the sample.

The following boundary and initial conditions are considered:

$$
\begin{gathered}
\text { at } t=0, \theta_{\mathrm{w}}=\theta_{0} \text {; for all } x \\
\text { when } t>0, \theta_{\mathrm{w}}=\theta_{\mathrm{s}} \text { at } x=0
\end{gathered}
$$

$\theta_{\mathrm{s}}$ being the value of $\theta_{\mathrm{w}}$ at saturation.

To solve Richard's equation, a finite difference program ${ }^{32,33}$ was used. An implicit scheme was tested on FoCa7 clay. 
In the following, we use the notation:

$$
\theta(i \Delta x, k \Delta t)=\theta_{i}^{k}
$$

where $\Delta x$ and $\Delta t$ are, respectively, space and time steps.

As no humidity exchange is permitted with the outer medium of the sample, we can take another boundary condition which is no flow at the head of the sample.

In the calculations, the difference between the case without swelling and the free swelling one is only in the form of the potential and then of the diffusion as discussed before.

To achieve the calculations, we had to introduce the values of several parameters. The initial and saturation water content were taken directly from the experiments. The permeability of the clay was experimentally measured by Imbert $^{28}$ using another specimen with the same characteristics. The suction potential was deduced from the water retention curve, which was also measured by Imbert independently by using saturated salt solutions to impose the suction values in the sample. The diffusion coefficient was calculated from those values using the relation:

$$
D_{\mathrm{m}}=-K \frac{\partial \psi_{\mathrm{m}}}{\partial \theta}
$$

Having determined these coefficients, the calculation of water transfer in the non-deformed case could be performed.

The calculation of free swelling case needed also the swelling potential term in order to evaluate the diffusion factors. It was derived from the experimental curves presented above giving the relation between water content and swelling pressure (Figure 11). The function obtained between the swelling diffusion and the water content has roughly an exponential form. Thus, the swelling potential was added to the suction potential to take into account the total potential in the sample. The total diffusion which was deduced from the total potential is presented in Figure 14. These calculations gave the moisture profiles versus time at every height in the samples, which could be compared to experimental results obtained by gamma spectroscopy. The results of calculation for the non-deformed matrix are presented in Figures 16 and 17, respectively, for the distances 3 and $13 \mathrm{~mm}$ from the bottom of the sample, as well as the experimental values.

The graphs indicate that the calculation results are acceptable compared to the experimental measures. The complete saturation of the specimen occurs after 3 months for numerical results, in agreement with experimental results.

The results presented in Figures 18 and 19 correspond to the comparison between our calculation with the conditions of free swelling, and the experimental data given in Reference 28 about water content profiles at two distances 3 and $51 \mathrm{~mm}$ from the bottom, $51 \mathrm{~mm}$ is the top of the clay sample for the same FoCa7 clay. These figures show a satisfactory agreement between calculations and experiments. In particular, the necessary time to achieve a complete saturation of the specimens is well predicted by the calculation.

We used the same model for undeformable matrix and for free swelling. The difference was only in the diffusion factors evaluation and so in the water potential considered in each case. The comparison between calculated and experiment results is satisfactory for the two cases. For the intermediate cases the actual formulation needs to be completed by a given stress-strain relationship of the clay particles, allowing us to compute the relation between the swelling pressure and the volume change of the clay specimen at a microscopic level. This point can be a logical following of this work. 


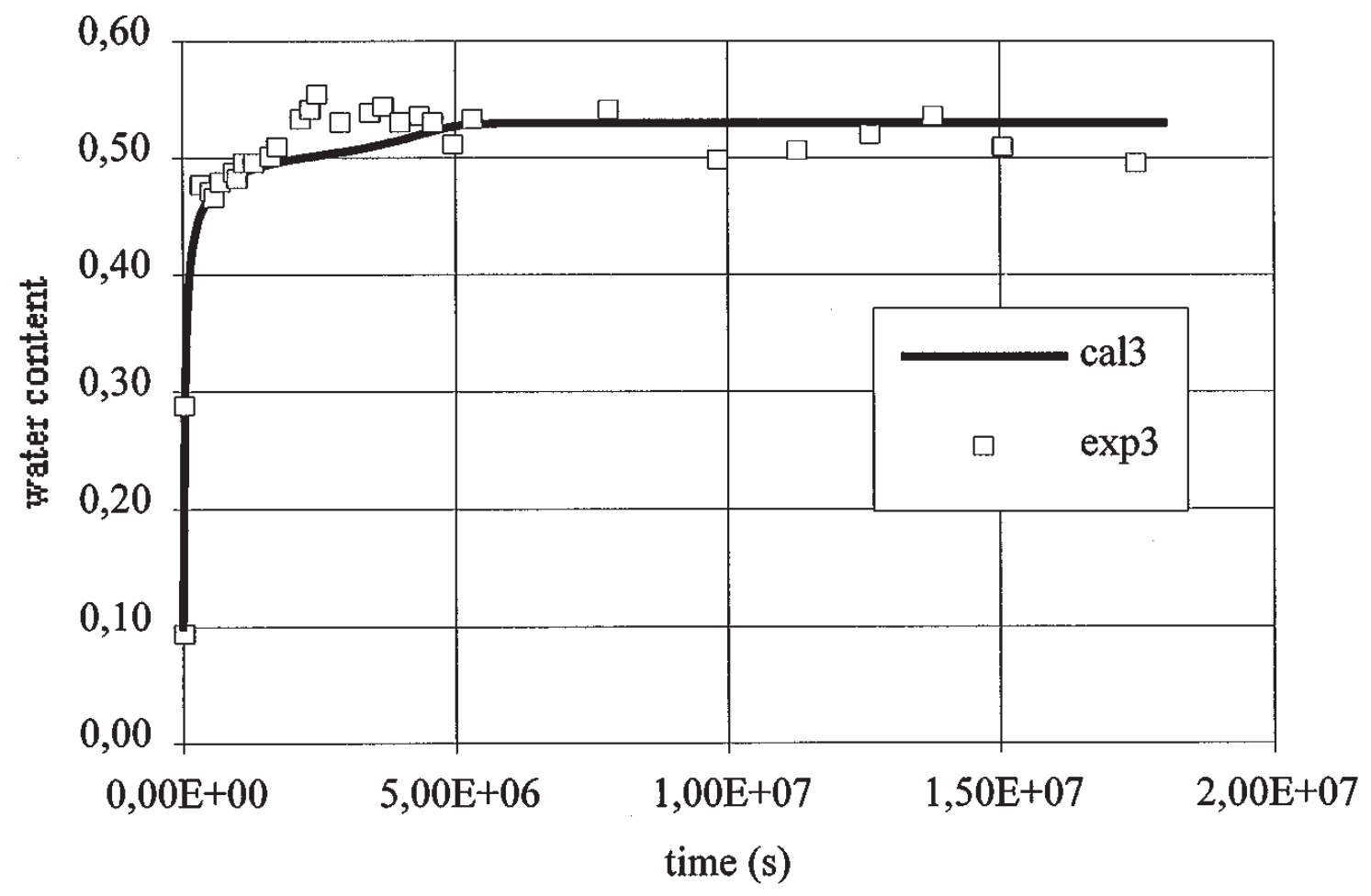

Figure 16. Prevented swelling moisture profiles versus time at $3 \mathrm{~mm}$ from the bottom; experiment and calculation

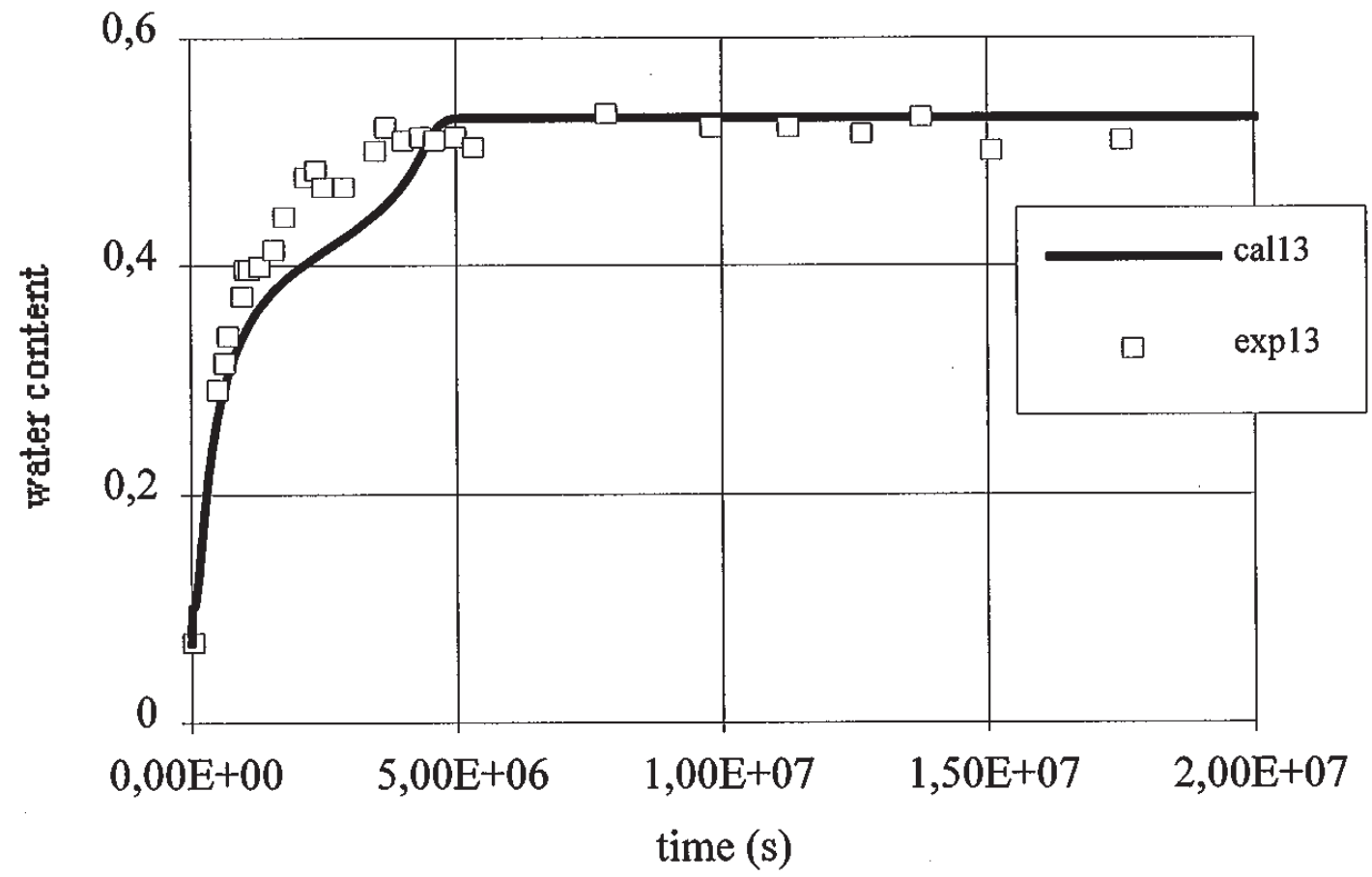

Figure 17. Prevented swelling moisture profiles versus time at $13 \mathrm{~mm}$ from the bottom; experiment and calculation

\section{CONCLUSIONS}

The experimental study of FoCa7 clay allowed us a better understanding of microscopic aspects of swelling. The X-ray method gave us the ability to follow the microstructure evolution of the clay samples during hydration. The conclusion about swelling is that it occurs in two stages with 


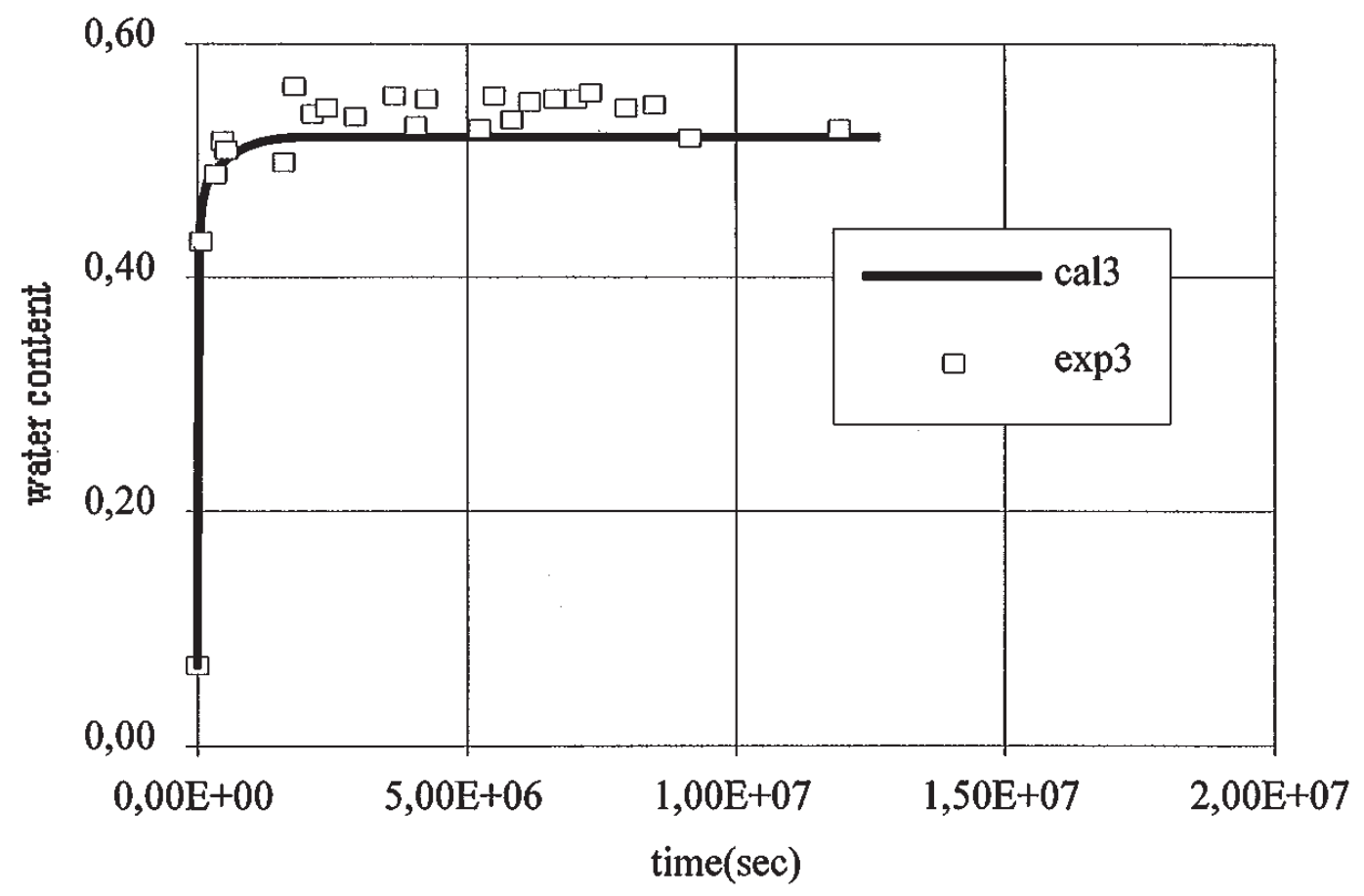

Figure 18. Free swelling moisture profiles versus time at $3 \mathrm{~mm}$ from the bottom; experiment and calculation

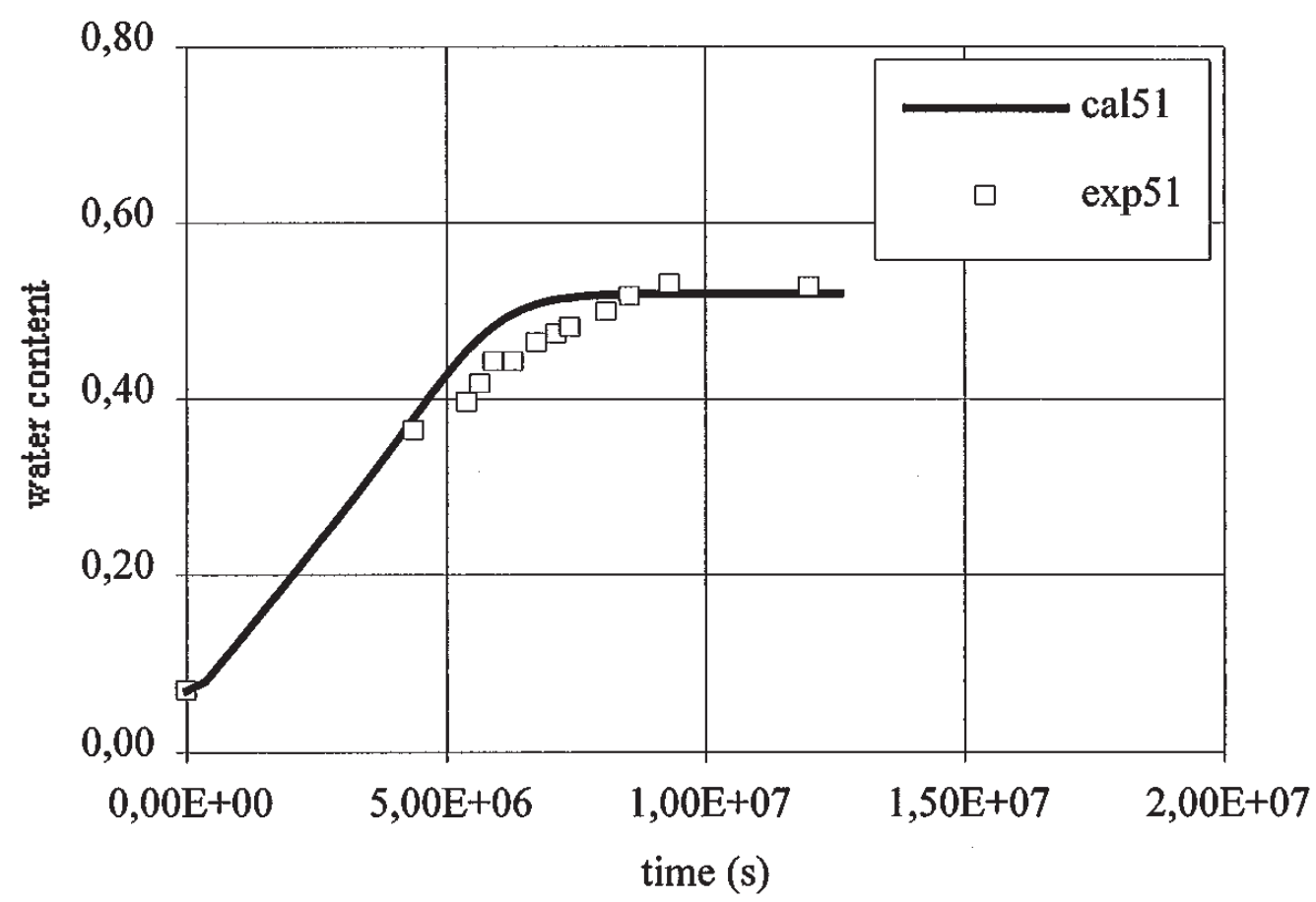

Figure 19. Free swelling moisture profiles versus time at $51 \mathrm{~mm}$ from the bottom; experiment and calculation

two mechanisms. The first one is when the insertion of organised water layers begins between the clay layers, it provokes the division of the initial particles. These water layers are very close to the surface layer. In the second stage, the smaller particles are separated by more water quantities causing a larger order of porosity, which are compatible with diffuse double layer existence around the hydrated clay layer. 
We demonstrated that the initial microstructure, i.e. before hydration, plays a key role in the mechanisms of the water adsorption. Our specimens were highly compacted (one dimensional compression up to $60 \mathrm{MPa}$ ). After swelling, when we measured the distances between clay layers by X-ray method we did not observe any distances exceeding $21 \AA$, which represents four water layers, while distances about $100 \AA$ were measured in the case of hydration of clay samples which were gels or powders (suspension after hydration). So we can say that the initial compaction of the samples provoked a very close structure which resisted the water insertion and lead to the division into smaller particles.

Using the results of the experimental analysis, we proposed a modelling of water transfer in unsaturated compacted clays. The results of calculation in the case of one directional hydration compared well to experimental results in conditions of non-deformed matrix and free swelling.

\section{ACKNOWLEDGEMENTS}

This work was supported by ANDRA (National Agency of nuclear waste management) under contracts.

\section{REFERENCES}

1. J. Mering, 'Sur le processus de l'hydration de la montmorillonite', Trans. Faraday Soc. XLH B (1946).

2. G. Kassif and A. Ben Shalom, 'Experimental relationship between swell pressure and suction', Geotechnique, 21(3), 245-255 (1971).

3. D. Tessier and J. Berrier, 'bservation d'argiles hydratées en microscopie électronique à balayage; importance et choix de la technique de préparation', Proc. 5th Int. Working Meeting Soil Micromorphology, Granada, pp. 1978, 117-135.

4. R. N. Yong, L. O. Taylor and B. P. Warkentin, 'Swelling pressure of sodium montmorillonite at depressed températures', Nat. Conf. Clays Clay Miner. Proc. 2, 268-281 (1963).

5. B. P. Warkentin, G. H. Bolt and R. D. Miller, 'Swelling pressure of montmorillonite', Soil Sci. Soc. Proc., (1957).

6. R. Kjellander, S. Marcelja, R. M. Pashley and J. P. Quirk, 'Double-layer ion correlation forces restrict Calcium-clay swelling', J. Phys. Chem., 92, 6489-6492 (1988).

7. R. N. Yong and A. M. O. Mohamed, 'A study of particle interaction energies in wetting of unsaturated expansive clays'. Geotechnical Research Center, McGILLS University, Montréal, 1992.

8. A. Delville and P. Laszlo, 'The origin of the swelling of clays by water', Am. Chem. Soc. Langmuir, 6(7), 1289-1294 (1990).

9. D. Tessier, 'Etude expérimentale de l'organisation des matériaux argileux', Thèse de Doctorat d'état, Univ. de Paris VII, 1984.

10. J. R. Philip, 'Numerical solution of equations of the diffusion type with diffusivity concentration-dependent', Trans. Faraday Soc., (51), 885-892 (1955).

11. J. R. Philip, 'The theory of infiltration: 1. the infiltration equation and its solution', Soil Sci., 345-357 (1956).

12. B. A. Schrefler, L. Simoni, L. Xikui and O. C. Zienkiewicz, 'Mechanics of partially saturated porous Media', in Numerical Methods and Constitutive Modeling in Geomechanics, CISM Lecture Notes, Desai and Gioda eds, Wien, 1990, pp. 169-209.

13. J. M. Piau, 'Rapport interne sur NSAT dans CESAR-LCPC, Laboratoire Central des Ponts et Chaussées, Paris, 1989.

14. A. Modaressi, N. Abou-Bekr and J. J. Fry, 'Unified approach to model partially saturated and saturated soil', Unsaturated Soils, Unsat '95, Paris, Vol. 3, 1996, pp. 1495-1502.

15. J. E. B. Jennings and J. B. Burland, 'Limitations to the use of effective stress in partly saturated soils', Géotechnique, 12(2), 125-144 (1962).

16. J. B. Burland, 'Some Aspects of Mechanical Behaviour of Partly Saturated Soils in Moisture Equilibria and Moisture Changes in Soil Beneath Covered Areas', Butterworth, Sydney, 1965, pp. 270-278.

17. E. L. Matyas and H. S. Radhakrishna, 'Volume change characteristics of partially saturated soil', Géotechnique, 18(4), 432-448 (1968).

18. D. G. Fredlund, 'Consolidation of unsaturated porous media', in Fundamentals of Transport Phenomena in Porous Media, J. Bear ed, NATO ASI SERIES, pp. 527-578 (1984).

19. A. Gens, 'Constitutive modeling of expansive soils', Proc. of Civil Eng. Unsaturated Soils: Recent Developments and Applications, Barcelona, Spain, 1993. 
20. M. D. Heilmen, D. L. Carter and C. L. Gonzalez, 'Ethylen glycol monoethyl ether for determining surface area of silicate minerals, Soil Sci., 100(5), 356-360 (1965).

21. Ch. H. Pons, 'Mise en évidence des relations entre la texture et la structure dans les systèmes eau-smectite par diffusion aux petits angles du rayonnement X synchrotron', Thèse, Univ. Orléans, 1980.

22. C. H. Pons, F. Rousseaux and D. Choubar, 'Utilisation du rayonnement synchrotron en diffusion aux petits angles pour l'étude du gonflement des smectites. I: Etude du système eau- montmorillonite-Na en fonction de la température', Clay Miner., 16, 23-42 (1981).

23. B. Delvaux, D. Tessier, A. Herbillon, G. Burtin, A. M. Jaunet and L. Vielvoye, 'Morphology, texture, and microstructure of Halloysiticsoil clays as related to weathering and exchangeable cation', Clays Clay Miner., 40(4), 446-456 (1992).

24. H. Ben Rhaeim, D. Tessier and Ch. H. Pons, 'Comportement hydrique et évolution structurale et texturale des montmorillonites au cours d'un cycle de dessiccation-humectation: Ca des montmorillonites calciques', Clay Miner., 21, 9-29 (1986).

25. N. Saiyouri, 'Microstructural approach and transfer water modelling and swelling in unsaturated clays', Ph.D. Thèse de l'Ecole Centrale de Paris, 1996.

26. M. Vauclin, 'Hydrodynamique dans les sols partiellement saturés déformables', Les Phénomènes de Transfert dans les Milieux Poreux Déformables, INRA, 1988.

27. G. Sposito, 'Steady of vertical flows in swelling soils' and 'A thermodynamical integral equation for the equilibrium moisture profile in swelling soil', Water Resource Res., 11, 461-464 and 499-500 (1975).

28. C. Imbert, 'Etude de l'hydratation uniaxiale d'échantillons d'argiles compactée par la méthode Gammadensitométrique double source', Report of ANDRA, N.T.SCS/93.45.DQCI, 21/12/93, 1993.

29. R. Allan Freeze, 'Three-dimensional, transient, saturated-unsaturated flow in a groundwater basin', Water Resources Res., 7(2), (1971).

30. R. Angulo-Jaramillo, 'Caractérisation hydro-dynamique de sols déformables partiellement saturés. Etude expérimentale à l'aide de la spectrométrie gamma double-source', Thèse de Mechanique de l'Institut Polytechnique de Grenoble, 1989.

31. T. Vicol, 'Comportement hydralique et mécanique d'un sol fin non saturé. Application à la modélisation', Thèse de l'Ecole Nationale des Ponts et Chaussées, 1990.

32. N. Saiyouri and P. Y. Hicher, 'Hydromechanical behaviour of expansive compacted clay during wetting', 2nd Int. Congress on Environmental Geotechnics. IS-Osaka '96, Osaka, Japan. 5-8 November 1996.

33. J. P. Nougier, Methodes de Calcul Numérique, Masson, 1991. 